\title{
Differentiation between pine woods according to species and growing location using FTIR-ATR
}

\author{
Mohamed Traoré ${ }^{1}$ (D) Joeri Kaal ${ }^{1,2} \cdot$ Antonio Martínez Cortizas ${ }^{1}$
}

Received: 16 December 2016/Published online: 4 November 2017

(C) The Author(s) 2017. This article is an open access publication

\begin{abstract}
Attenuated total reflectance-Fourier transform infrared (FTIR-ATR) spectroscopy was applied to 120 samples of heartwood rings from eight individual pine trees from different locations in Spain. Pinus sylvestris cores were collected at the Artikutza natural park (Ps-ART). Pinus nigra cores were collected in Sierra de Cazorla (Pn-LIN) and in La Sagra Mountain (Pn-LSA). Three discriminant analysis tests were performed using all bands $\left(\mathrm{DF}_{\mathrm{T}}\right)$, lignin bands only $\left(\mathrm{DF}_{\mathrm{L}}\right)$ and polysaccharides bands only $\left(\mathrm{DF}_{\mathrm{P}}\right)$, to explore the ability of FTIR-ATR to separate between species and growing location. The $\mathrm{DF}_{\mathrm{L}}$ model enabled a good separation between pine species, whereas the $\mathrm{DF}_{\mathrm{P}}$ model enabled differentiation for both species and growing location. The $\mathrm{DF}_{\mathrm{T}}$ model enabled virtually perfect separation, based on two functions involving twelve FTIR bands. Discrimination between species was related to bands at 860 and $1655 \mathrm{~cm}^{-1}$, which were more intense in $P$. sylvestris samples, and bands at 1425 and $1635 \mathrm{~cm}^{-1}$, more intense in $P$. nigra samples. These vibrations were related to differences in lignin structure and polysaccharide linear chains. Discrimination between growing locations was mainly related to polysaccharide absorptions: at 900,1085 and $1335 \mathrm{~cm}^{-1}$ more representative of Pn-LIN samples, and at 1105 and $1315 \mathrm{~cm}^{-1}$ mostly associated to Pn-LSA samples. These absorptions are related to $\beta$-glycosidic linkages $\left(900 \mathrm{~cm}^{-1}\right)$, cellulose and hemicellulose (C-O bonds, 1085 and $1105 \mathrm{~cm}^{-1}$ ) and content in amorphous/crystalline cellulose $\left(1315\right.$ and $\left.1335 \mathrm{~cm}^{-1}\right)$. These results show that FTIR-ATR in combination with multivariate statistics can be a useful tool for species identification and provenancing for pine wood samples of unknown origin.
\end{abstract}

\section{Mohamed Traoré}

mohamed.traore@usc.es; traore.mohamed19@gmail.com

1 Ciencia do Sistema Terra, Departamento de Edafoloxía e Química Agrícola, Universidade de Santiago de Compostela, Campus Sur s/n, 15782 Santiago de Compostela, Spain

2 Instituto de Ciencias del Patrimonio (Incipit), Consejo Superior de Investigaciones Científicas (CSIC), San Roque 2, 15704 Santiago de Compostela, Spain 


\section{Introduction}

Wood is one of the most used materials for construction, furniture and other purposes (Holmgren et al. 1999; Tiscar and Linares 2011). It is a complex lignocellulosic material composed of cellulose, hemicellulose, lignin and extractives. Softwood from gymnosperms and hardwood from angiosperms are the major types of timber (Wing 2015). In the cross section of stems of many mature trees, two distinct regions can be distinguished, the sapwood (outer zone) and the heartwood (inner zone), the latter of which is usually relatively dark-coloured. The heartwood is composed of dead cells and usually has a darker appearance due to the abundance of extractive compounds such as tannin and terpenoids (Unger et al. 2001; Pandey 2005). The structural strength of heartwood enhances its durability, and heartwood is more resistant against environmental degradation processes such as irradiation and attack by fungi or other microorganisms as well (Taylor et al. 2002). Therefore, heartwood has been used rather than sapwood for most applications. In conifers such as Pinus sp., the heartwood has a high occurrence of resin ducts, which distribute water and resinous substances. Oleoresin composed of volatile (monoand sesquiterpenes) and non-volatile (diterpene: resin acid) resin is secreted by the duct to protect against insects and pathogens (Manninen et al. 2002).

During the modern age era, Iberian shipbuilders used pine timbers for planking and hulls (Castro 2008; Tiscar and Linares 2011), primarily from the dominant pine species in the Iberian Peninsula (Oliva et al. 2006; Tiscar and Linares 2011; Krakau et al. 2013), i.e. Scots pine (Pinus sylvestris) and black pine (Pinus nigra). These two types of pine occur preferentially on alkaline soils and have similar growth habitats (Reyes and Casal 2004). Even though these species can be easily differentiated according to morphological features related to their cones, needles and bark (Enescu et al. 2016; Houston Durrant et al. 2016), the species of archaeological timbers from the Pinus genus are not easily identified. To the authors' knowledge, there are no studies based on wood chemical composition to distinguish between these pine species. From previous studies on shipwreck materials, it was shown that infrared spectroscopy combined with statistical methods could be a useful tool for species differentiation (Traoré et al. 2016), which is very important regarding archaeological wood studies. The present work is the first attempt to deal with spectroscopic fingerprinting to distinguish between two Pinus species because of the ability of Fourier transform infrared (FTIR) spectroscopy to provide information on dominant functional groups present in wood samples.

FTIR is a powerful technique for wood characterization, providing details on functional groups and molecular bonds (Evans 1991; Pandey 1999; Popescu et al. 2007; Esteves et al. 2013), which are useful to identify wood parts, wood type and also assessment of wood quality (Moore and Owen 2001; Gandolfo et al. 2016). Due to the complexity of wood, most of the infrared bands cannot be directly assigned to a single component. Multivariate statistical techniques can be used to improve FTIR spectral analysis (Chen et al. 2010). For example, principal component analysis (PCA) has been applied to determine chemical differences between earlywood and latewood (Hori and Sugiyama 2003), or to distinguish between trees growing at 
different locations (Rana et al. 2008; Santoni et al. 2015). In a previous work, PCA was applied to transposed data matrices to study the effects of oxic and anoxic environmental conditions on archaeological wood composition (Traoré et al. 2016). Other multivariate statistics such as principal components regression (PCR), partial least squares (PLS) and discriminant analysis have also proven useful for translating variability in FTIR spectra to information on wood chemistry (Faix and Böttcher 1993; Bjarnestad and Dahlman 2002; Boeriu et al. 2004; Carballo-Meilán et al. 2016).

The aim of the present study is to differentiate between woods from two pine species ( $P$. sylvestris and $P$. nigra) and trees growing at different locations in the Iberian Peninsula using FTIR-ATR in combination with stepwise discriminant analysis. The ability to distinguish between wood species and source area would be a valuable contribution to the discipline of provenancing archaeological timbers, and particularly to the assessment of the economy of Iberian shipbuilding wood of the XVI-XVII centuries (ForSEAdiscovery project, http://forseadiscovery.eu/).

\section{Materials and methods}

\section{Description of samples}

Eight individual trees of two pine species, Pinus nigra (black pine) and Pinus sylvestris (Scots pine) were studied, regarded as the most used ones for shipbuilding during the early modern era in southern Spain (Holmgren et al. 1999; Wing 2015).

In November 2014, six black pine trees were sampled in two different forests located in south-eastern Spain, in the region of Andalusia (Fig. 1). In Sierra de

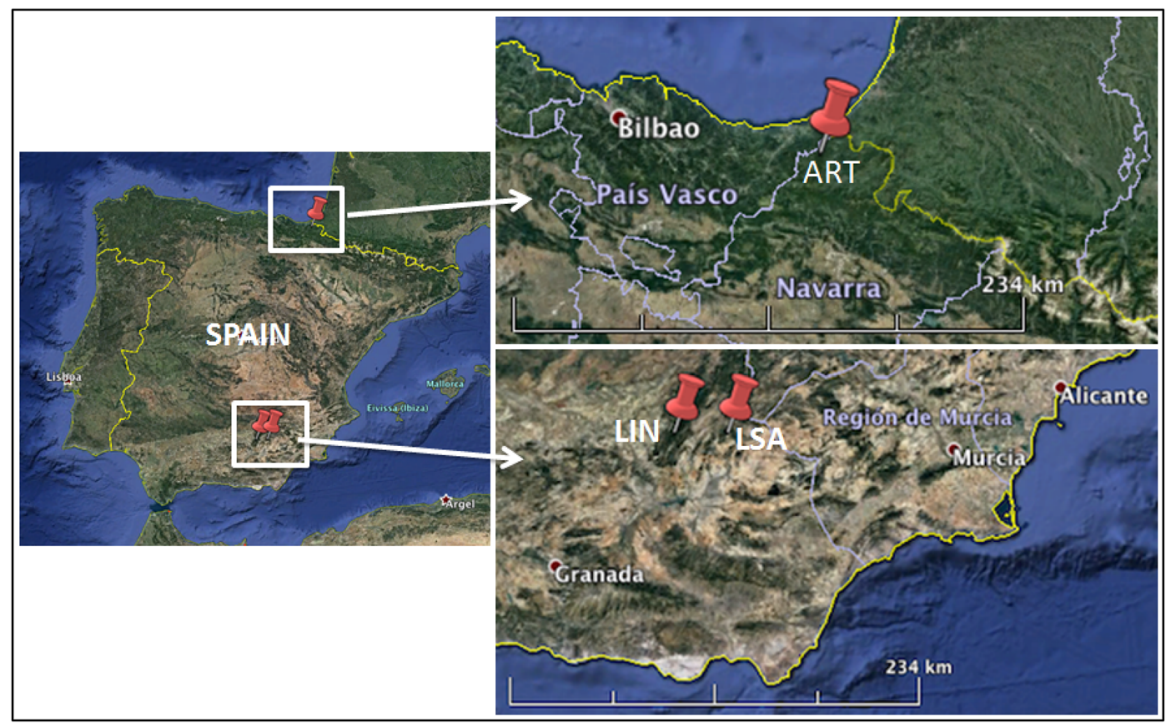

Fig. 1 Map of the sampling locations (LSA La Sagra Mountain, LIN Linarejos, ART Artikutza) 
Cazorla the sampling was performed in the municipality of Linarejos (Pn-LIN), between 1100 and $1250 \mathrm{~m}$ above sea level (m a.s.1.). The forest in La Sagra Mountain (Pn-LSA) is located between 1800 and $2000 \mathrm{~m}$ a.s.l. Finally, two Scots pine trees were collected in May 2015 at the Artikutza (Ps-ART) natural park in the Basque Country (northern Spain, Fig. 1) between 450 and $500 \mathrm{~m}$ a.s.l.

The samples were collected from 100 to 150 years old trees. Wood cores were retrieved using an increment borer, at breast height and transported and stored in paper tubes. Prior to the analysis, the wood cores were oven dried at $30{ }^{\circ} \mathrm{C}$ for 2 weeks. Then, the surfaces were clean-cut on both sides to visualize tree ring patterns. Clearing the surfaces was necessary to improve the visibility of thin tree rings and to limit the effects of resin bleed.

Chemical treatment of wood samples was also performed to identify FTIR signals of resin, lignin and polysaccharides. For this purpose, $1.0 \mathrm{~g}$ of wood was ball-milled to powder and the extractives were obtained by extraction of $50 \mathrm{ml} \mathrm{1:1}$ toluene:EtOH solvent, followed by evaporation of the solvent. The residue was subjected to the classical $72 \%$ sulphuric acid treatment ("Klason lignin"), which eliminates polysaccharides. For details, refer to Rowell et al. (2005).

\section{Fourier transform infrared spectroscopy}

For FTIR-ATR analyses, an Agilent Cary 630 FTIR Spectrometer equipped with a single-reflection diamond crystal was used. The spectra were collected in the absorbance range from 4000 to $400 \mathrm{~cm}^{-1}$ over 100 scans per sample, at a resolution of $4 \mathrm{~cm}^{-1}$.

Each wood core was cut ring by ring, and the FTIR measurements were taken on individual rings aiming to improve the contact between the sample and the diamond crystal of the FTIR equipment. However, for sections with very thin rings, several rings were analysed together. In this study, only data for the heartwood rings are presented and discussed, because this part is most commonly used as high quality timber, and because previous studies have shown that the differences in composition between sapwood and heartwood would otherwise dominate the variability (Traoré et al. 2016). For each tree, 15 spectra were recorded on randomly selected heartwood rings. In total, the data analysis was carried out on 120 spectra from 8 individual trees (see Table 1).

\section{Data analysis}

Focus was put on the fingerprint region between 1800 and $800 \mathrm{~cm}^{-1}$ where most of the variations of the molecular bond vibrations occur (Pandey and Pitman 2003). In the untransformed absorbance spectra, many peaks are difficult to identify due to overlap. Therefore, the second derivative spectra were used for band selection using Resolutions Pro 5.3.0.0 of Agilent Technologies. The assignment of bands to specific molecular structures was based primarily on available literature (see Table 2). Principal component analysis (PCA) was also applied to the transposed data matrix to support the assignation of the infrared bands. This PCA allows for the identification of bands with similar variability, which is arguably indicative of a 
Table 1 Samples used in the present study

\begin{tabular}{llllll}
\hline No. & Sites & Site codes & Tree ID & Species & No. recorded spectra \\
\hline 1 & Artikutza & Ps-ART & Ps-ART-A & P. sylvestris & 15 \\
2 & Artikutza & Ps-ART & Ps-ART-B & P. sylvestris & 15 \\
3 & Linarejos (plot 1) & Pn-LIN01 & Pn-LIN01-A & P. nigra & 15 \\
4 & Linarejos (plot 1) & Pn-LIN01 & Pn-LIN01-B & P. nigra & 15 \\
5 & Linarejos (plot 3) & Pn-LIN03 & Pn-LIN03-A & P. nigra & 15 \\
6 & Linarejos (plot 3) & Pn-LIN03 & Pn-LIN03-B & P. nigra & 15 \\
7 & La Sagra & Pn-LSA & Pn-LSA-A & P. nigra & 15 \\
8 & La Sagra & Pn-LSA & Pn-LSA-B & P. nigra & 15 \\
& & & & Total & 120 \\
\hline
\end{tabular}

common precursor (López-Merino et al. 2012; Traoré et al. 2016). Moreover, FTIR was also performed on the individual wood constituents by isolation of extractives ("resin") and the lignin residue after $\mathrm{H}_{2} \mathrm{SO}_{4}$ treatment (Klason lignin). The differential spectrum between the residue after resin extraction (lignin and polysaccharides) and the residue after acid digestion (lignin) is assumed to represent the polysaccharide fraction. Stepwise discriminant analysis was carried out on absorption data to determine the bands that allow differentiating between groups of samples. For the discriminant analyses, the spectra of each sample were used as input data, thus without grouping the 15 spectra of the individual trees. For the first discriminant analysis, two analyses were performed on lignin $\left(\mathrm{DF}_{\mathrm{L}}\right)$ and polysaccharide $\left(\mathrm{DF}_{\mathrm{P}}\right)$ bands separately, in order to identify the specific influence of these main wood components on the discrimination between samples. Secondly, all the selected bands were used in a global model $\left(\mathrm{DF}_{\mathrm{T}}\right)$, coding samples by species and forest location. For that purpose, from each individual tree $80 \%$ of the measurements (twelve spectra) were randomly used as training set ( $t$ ) and the remaining 20\% (three spectra) as validation set (v) to assess the accuracy of the discriminant models.

One-way ANOVA was carried out to assess the significance of the differences between tree species and forest locations. The classification by homogenous subsets was done by the post hoc test of Student-Newman-Keuls, with alpha $=0.05$. All statistical tests were done using SPSS 20.

\section{Results and discussion}

\section{Absorbance and second derivative spectra}

Figure 2a shows the average FTIR spectra in the fingerprint region (between 1800 and $800 \mathrm{~cm}^{-1}$ ) of the pine heartwood samples. The strong absorbance at 1690 and $1025 \mathrm{~cm}^{-1}$, and moderate to weak absorbance at 1590, 1510, 1460, 1380, 1265, $1155,1105,900$ and $825 \mathrm{~cm}^{-1}$, are associated with the major biopolymers of wood, i.e. cellulose, hemicellulose and lignin (see Table 2). Furthermore, the band at 
Table 2 Infrared bands and related molecular bond assignments

\begin{tabular}{|c|c|c|c|}
\hline No. & $\begin{array}{l}\text { Bands } \\
\left(\mathrm{cm}^{-1}\right)\end{array}$ & Band assignments (References) & $\begin{array}{l}\text { PCA } \\
\text { factor }^{\mathrm{a}}\end{array}$ \\
\hline 1 & 805 & $\begin{array}{l}\text { Vibration of mannan in hemicellulose and } \mathrm{CH} \text { out of plane bending in } \\
\text { phenyl rings (Evans et al. 1992) }\end{array}$ & $\mathrm{PC} 1$ \\
\hline 2 & 825 & $\mathrm{CH}$ out of plane bending in guaiacyl units (Faix 1991) & PC3 \\
\hline 3 & 860 & $\begin{array}{l}\text { C-H out of plane in position 2, 5, and } 6 \text { of guaiacyl units (Faix 1992; } \\
\text { Boeriu et al. 2004) }\end{array}$ & PC3 \\
\hline 4 & 900 & $\begin{array}{l}\text { CH deformation of beta-glycosidic linkages in cellulose (Evans et al. 1992; } \\
\text { Faix and Böttcher 1992) }\end{array}$ & PC1 \\
\hline 5 & 945 & O-H out of plane deformation in carboxylic acid (Shearer 1989) & $\mathrm{PC} 2$ \\
\hline 6 & 960 & $\begin{array}{l}\text { CH out of plane deformation in lignin (Popescu et al. 2007; Gandolfo et al. } \\
\text { 2016) }\end{array}$ & PC3 \\
\hline 7 & 985 & CO stretching in cellulose (Herrera et al. 2014) & PC1 \\
\hline 8 & 1005 & $\mathrm{C}-\mathrm{O}$ stretch in cellulose (Liang and Marchessault 1959) & PC1 \\
\hline 9 & 1025 & $\mathrm{C}-\mathrm{O}$ stretching in primary alcohols in cellulose (Popescu et al. 2007) & PC1 \\
\hline 10 & 1055 & C-O stretching of secondary alcohols (Faix 1991) & PC1 \\
\hline 11 & 1105 & $\begin{array}{l}\text { C-O-C stretching in cellulose and hemicellulose (McCann et al. 1992; } \\
\text { Zhang et al. 2010) }\end{array}$ & PC1 \\
\hline 12 & 1155 & $\begin{array}{l}\text { C-O-C asymmetric stretching in cellulose and hemicellulose (Faix and } \\
\text { Böttcher 1992; Popescu et al. 2007) }\end{array}$ & PC1 \\
\hline 13 & 1185 & C-O stretching in Cellulose (Zhou et al. 2015) & PC1 \\
\hline 14 & 1225 & $\begin{array}{l}\text { OH vibration in guaiacyl ring, } \mathrm{C}-\mathrm{C}, \mathrm{C}-\mathrm{O} \text {, and } \mathrm{C}=\mathrm{O} \text { stretches in lignin } \\
\text { (Chen et al. 2010; Zhou et al. 2015) }\end{array}$ & - \\
\hline 15 & 1265 & C-O vibration in guaiacyl rings (Popescu et al. 2007; Chen et al. 2010) & PC3 \\
\hline 16 & 1315 & $\begin{array}{l}\mathrm{CH}_{2} \text { wagging in crystalline cellulose (Colom and Carrillo 2005; Popescu } \\
\text { et al. 2007) }\end{array}$ & PC1 \\
\hline 17 & 1335 & $\begin{array}{l}\text { CH of methyl groups in methoxy in amorphous cellulose (Colom and } \\
\text { Carrillo 2005; Popescu et al. 2007) }\end{array}$ & - \\
\hline 18 & 1360 & $\begin{array}{l}\text { C-H deformation in cellulose and hemicelluloses (Evans et al. 1992; } \\
\text { Mohebby 2008) }\end{array}$ & PC1 \\
\hline 19 & 1385 & C-O stretching in cellulose and hemicellulose (Labbé et al. 2006) & - \\
\hline 20 & 1405 & $\mathrm{C}=\mathrm{O}$ in carboxylic groups in carboxylic acid, ester (Zhang et al. 2010) & $\mathrm{PC} 2$ \\
\hline 21 & 1425 & $\begin{array}{l}\text { C-H asymmetric deformation in methoxyl, aromatic skeletal vibrations, } \\
\text { lignin (Faix 1992; Popescu et al. 2007) }\end{array}$ & PC3 \\
\hline 22 & 1465 & $\begin{array}{l}\mathrm{C}-\mathrm{H} \text { asymmetric deformation in methoxyl for lignins, asymmetric in- } \\
\mathrm{CH}_{3} \text { and } \mathrm{CH}_{2} \text { in pyran for hemicellulose (Popescu et al. 2007; Chen et al. } \\
\text { 2010) }\end{array}$ & PC3 \\
\hline 23 & 1510 & $\begin{array}{l}\mathrm{C}=\mathrm{C} \text { stretching of the aromatic ring, } \mathrm{C}=\mathrm{O} \text { bond vibrations in extractive } \\
\text { compounds (Popescu et al. 2007; Zhou et al. 2015) }\end{array}$ & PC3 \\
\hline 24 & 1590 & $\begin{array}{l}\text { Skeletal vibrations from the C-C (Kubo and Kadla 2005; Vahur et al. } \\
\text { 2011) }\end{array}$ & PC3 \\
\hline 25 & 1610 & $\begin{array}{l}\mathrm{C}=\mathrm{O} \text { stretching conjugated to the aromatic ring, and in carboxylic groups } \\
\text { in lignin, carboxylic acid, ester compounds ( } \mathrm{Zhao} \text { et al. 2014) }\end{array}$ & - \\
\hline
\end{tabular}


Table 2 continued

\begin{tabular}{|c|c|c|c|}
\hline No. & $\begin{array}{l}\text { Bands } \\
\left(\mathrm{cm}^{-1}\right)\end{array}$ & Band assignments (References) & $\begin{array}{l}\text { PCA } \\
\text { factor }^{\mathrm{a}}\end{array}$ \\
\hline 26 & 1635 & $\begin{array}{l}\text { Absorbed O-H and conjugated C-O in polysaccharides (Genest et al. } \\
\text { 2013; Karunakaran et al. 2015) }\end{array}$ & - \\
\hline 27 & 1655 & $\begin{array}{l}\text { Absorbed O-H and conjugated C-O in polysaccharides (Genest et al. } \\
\text { 2013; Karunakaran et al. 2015) }\end{array}$ & - \\
\hline 28 & 1690 & $\begin{array}{l}\mathrm{C}=\mathrm{O} \text { vibration in carboxylic group in resin acid (Mizzoni and Cesaro 2007; } \\
\text { Vahur et al. 2011) }\end{array}$ & PC2 \\
\hline 29 & 1730 & $\begin{array}{l}\mathrm{C}=\mathrm{O} \text { carbonyls in ester groups and acetyl group in xylan (Bodirlau and } \\
\text { Teaca 2009; Zhou et al. 2015) }\end{array}$ & PC1 \\
\hline
\end{tabular}

${ }^{a}$ Band assignment related to PCA factors (see Fig. 3: PC1 for polysaccharides, PC2 for terpenoids and PC3 for lignin)

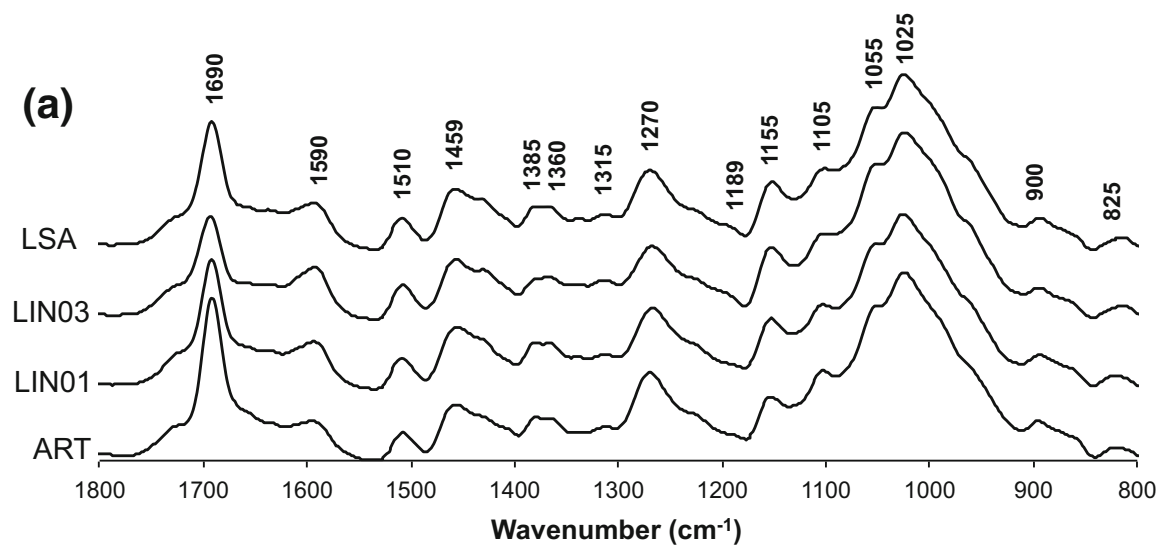

(b)

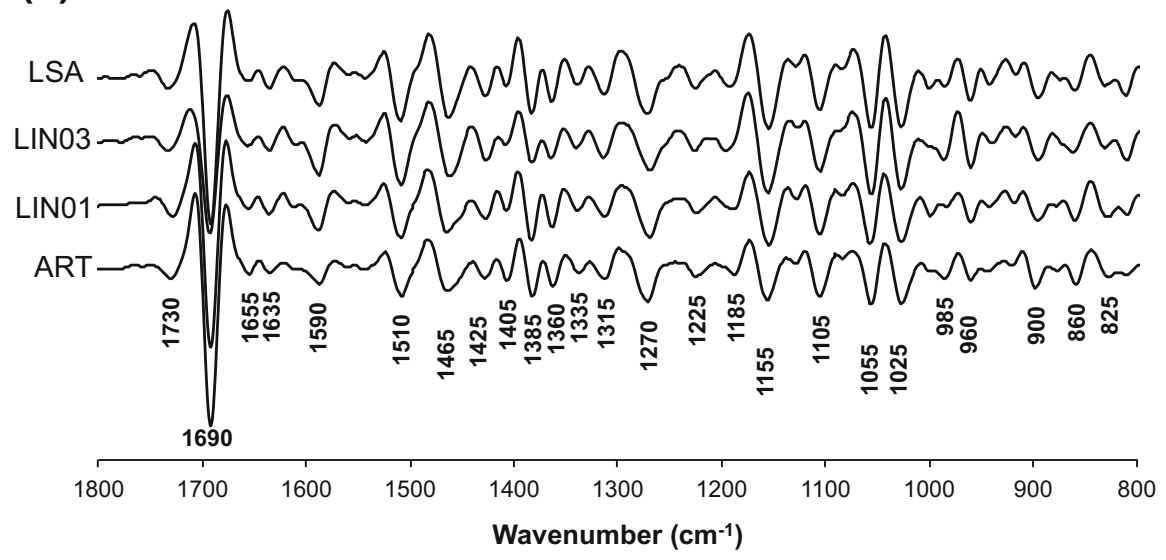

Fig. 2 Average spectra (a) and second derivative spectra (b) of the heartwood samples (LSA La Sagra Mountain, LINO1 and LINO3 Linarejos plot 01 and 03, ART Artikutza) 
Fig. 3 FTIR spectra of individual wood components (extracted resin, isolated lignin and carbohydrates from the difference spectrum of solvent-extracted wood and Klason lignin isolate), and the plot of component scores of the three first extracted factors from principal component analysis applied to the transposed data matrix (samples as variables)

$1690 \mathrm{~cm}^{-1}$ is specific to resin acid compounds (Nuopponen et al. 2003; Vahur et al. 2011).

In the second derivative spectra, many bands are identified more easily (Fig. 2b) confirming previous studies using the second derivative (Boeriu et al. 2004; Huang et al. 2008; Popescu et al. 2009; Zhang et al. 2016). The identified bands are listed with their most likely sources (based on literature) in Table 2. Most of the bands were assigned to lignin $(825,860,960,1225,1265,1425,1465,1510$ and $\left.1590 \mathrm{~cm}^{-1}\right)$ and polysaccharides $(805,900,985,1005,1025,1055,1105,1155$, 1185, 1315, 1335, 1360, 1385, 1635, 1655 and $1730 \mathrm{~cm}^{-1}$ ) (Faix 1991; Pandey 1999; Schwanninger et al. 2004). In general, the FTIR spectra of individual wood components (extractives, polysaccharides and lignin) support the band assignments given above. The FTIR spectrum of the extractives showed that it is composed almost exclusively of resinous materials (no bands from, e.g. tannin identified). Furthermore, the first three principal components from the PCA (accounting for $99 \%$ of the variation in the dataset) show striking resemblance with the spectra of the chemically isolated wood components (see Fig. 3 and also in Table 2). More specifically, $\mathrm{PC} 1$ is associated with polysaccharides (with higher scores for $\mathrm{C}-\mathrm{O}$ bonds), PC2 with terpenoid constituents (high scores for carbonyl bonds) and PC3 with lignin (high scores for aromatic structural vibrations) (Fig. 3; Table 2). It is concluded that a combination of (1) comparison with band assignments from literature, (2) PCA of the whole dataset, and (3) chemical treatments for obtaining reference materials allowed for a very reliable identification of the primary structures responsible for the bands, including the minor ones, discussed in this study.

\section{Discriminant analysis}

\section{Discrimination based on lignin and polysaccharide absorption bands separately}

The stepwise discriminant analysis applied to the bands that were assigned to lignin $\left(\mathrm{DF}_{\mathrm{L}}\right.$ ) presented a clear separation (Fig. 4a) between Pinus sylvestris (Ps-ART) and Pinus nigra samples (Pn-LIN and Pn-LSA) on the first discriminant function $\left(\mathrm{DF} 1_{\mathrm{L}}\right)$, which showed highest loadings for bands at 860, 1265, 1425, 1465 and $1510 \mathrm{~cm}^{-1}$. However, the distinction between the two Pinus nigra locations was poor. Using these four bands, the discriminant analysis was performed again coding only for species (Pinus sylvestris vs. Pinus nigra) in order to confirm the discrimination between them. The results showed a clear separation between PsART samples, with positive scores, and Pn-LIN and Pn-LSA samples, with negative scores (data not shown).

The discriminant analysis on the bands related to polysaccharides $\left(\mathrm{DF}_{\mathrm{P}}\right)$ provided a good separation (Fig. 4b) between species on the first discriminant function 

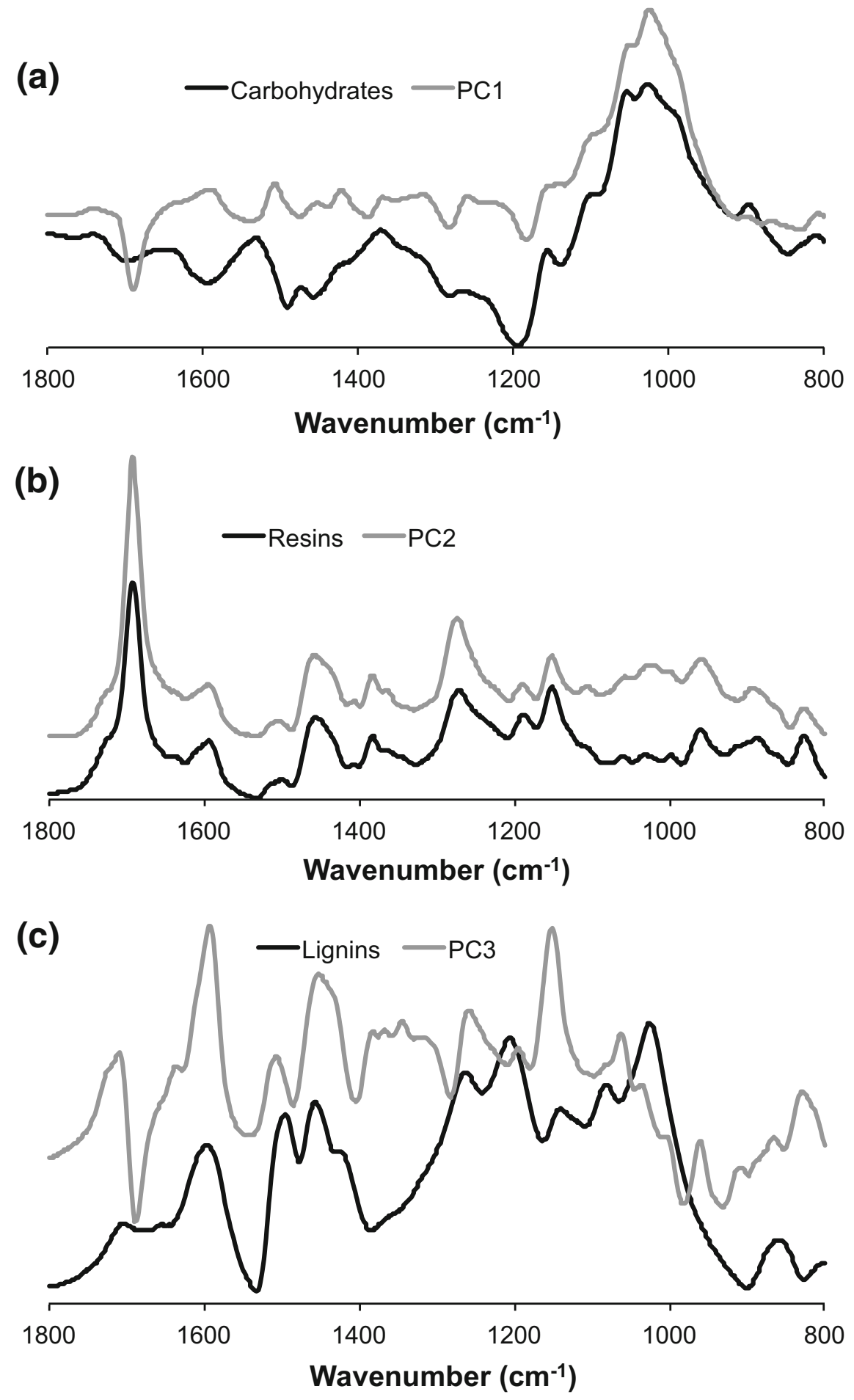
(a)

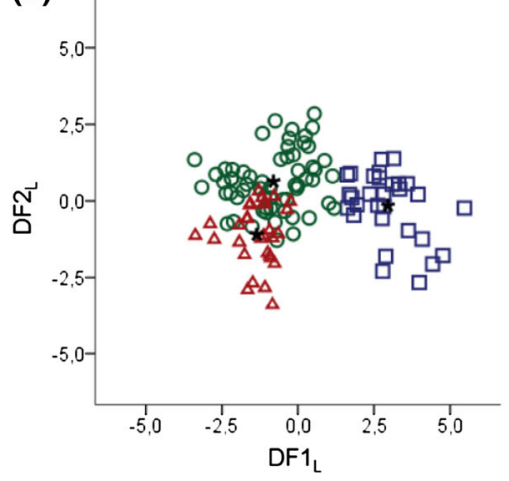

(b)

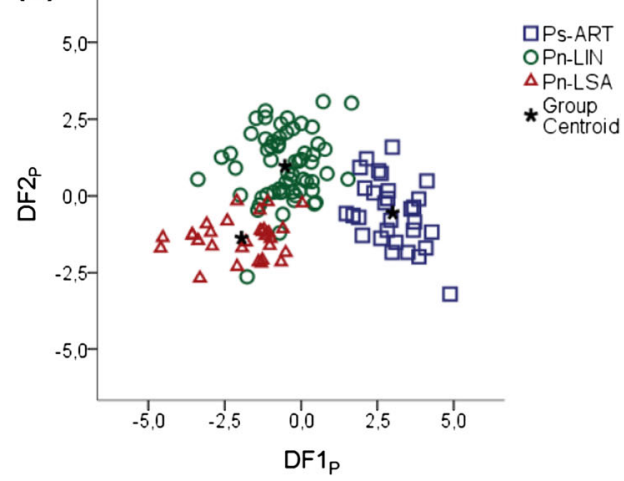

Fig. 4 Plot of the canonical functions obtained in the discriminant analysis applied to lignin absorption bands (a) and polysaccharide absorption bands (b)

$\left(\mathrm{DF} 1_{\mathrm{P}}\right)$ and the two locations of Pinus nigra (Pn-LIN and Pn-LSA) were separated by the second discriminant function $\left(\mathrm{DF} 2_{\mathrm{P}}\right)$. The associated bands are 805,900 , $1105,1155,1187,1315,1335,1383,1635$ and $1655 \mathrm{~cm}^{-1}$. To confirm the discrimination related to forest location, another analysis was performed using only samples from Pinus nigra (Pn-LIN and Pn-LSA). Again, the results showed good separation, Pn-LIN samples showing positive and Pn-LSA samples negative scores.

\section{Stepwise discriminant analysis with all absorption bands}

The $\mathrm{DF}_{\mathrm{T}}$ provided two discriminant functions that are based on twelve infrared bands $(860,900,1105,1225,1315,1335,1385,1405,1425,1610,1635$, $\left.1655 \mathrm{~cm}^{-1}\right)$. The first function $\left(\mathrm{DF}_{\mathrm{T}}\right)$ explains $82 \%$ of the total variance while the second function $\left(\mathrm{DF}_{\mathrm{T}}\right)$ accounts for the remaining $18 \%$. The projection of the two functions (Fig. 5) shows that the samples plot in three main groups: Ps-ART, composed of samples of Pinus sylvestris trees from the Artikutza natural park; PnLIN, composed of samples of Pinus nigra trees from Linarejos, and Pn-LSA, composed of samples of Pinus nigra trees from La Sagra Mountain. Hence, $\mathrm{DF} 1_{\mathrm{T}}$ (0.94 canonical correlation) showed a clear separation between the samples of the training set of Ps-ART, with positive scores, and the samples of the training sets of Pn-LIN and Pn-LSA, which have predominantly negative scores. The ANOVA test indicated that this difference is significant $(P<0.001)$ for $\mathrm{DF} 1_{\mathrm{T}}$ scores (differences between pine species), as observed from boxplots (Fig. 6a). The DF $2_{\mathrm{T}}(0.80$ canonical correlation) showed a clear separation between samples of the training sets of Pn-LIN and Pn-LSA, with positive scores for Pn-LIN and negative scores for Pn-LSA, albeit that there is some overlap between the clusters of Pn-LIN and PnLSA. A highly significant difference $(P<0.001)$ was also found for $\mathrm{DF} 2_{\mathrm{T}}$ scores (differences between locations for Pinus nigra trees) (Fig. 6b).

The validation set confirmed the accuracy of the discrimination between species and sampling locations. For the species differentiation $\left(\mathrm{DF}_{\mathrm{T}}\right)$, Pinus sylvestris and 


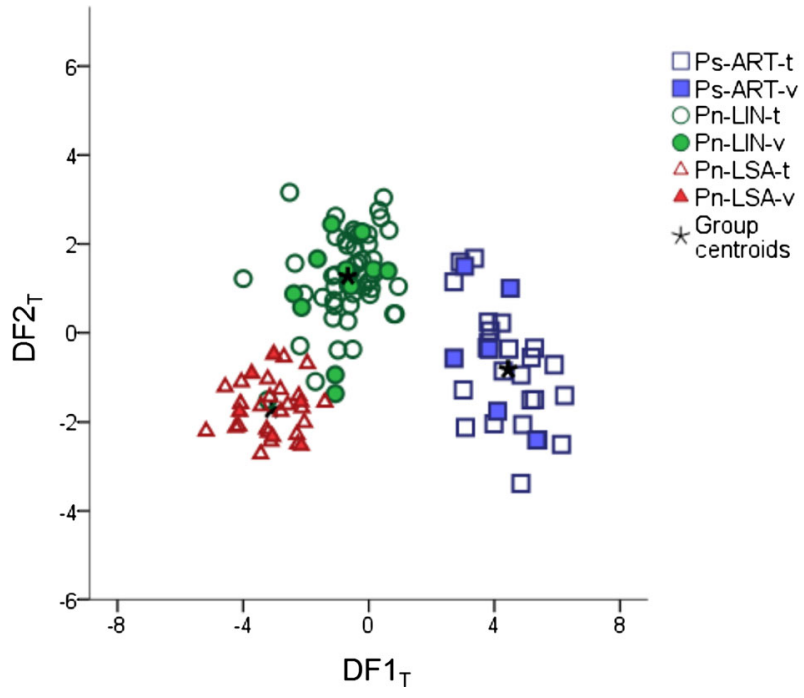

Fig. 5 Plot of the canonical functions obtained by the discriminant analysis with all absorption bands (t for training set and $\mathrm{v}$ for validation set)

Pinus nigra samples of the validation set were all correctly identified, with an average probability of $0.99 \pm 0.01(\mathrm{AVG} \pm \mathrm{SD})$; the same was found for each individual group of samples [Ps-ART-v $(n=6)$, Pn-LIN-v $(n=12)$ and Pn-LSA-v $(n=6)]$. As for the growing location $\left(\mathrm{DF}_{\mathrm{T}}\right)$, the samples of the validation sets of the two sites of Pinus nigra showed an average probability of correct site identification of 0.91 (SD 0.22). More specifically, samples from Pn-LIN-v were correctly assigned to their location with an average probability of $0.87 \pm 0.26$, whereas the probability for Pn-LSA-v was $0.99 \pm 0.01$. The lower probability for the Pn-LIN-v samples suggests that there is more variability in wood composition in the trees from this site. Even though it is known that the composition of arboreal wood depends on environmental factors of the growing location (Fritts 1976; Creber and Chaloner 1984), this variability can also be related to the sampling strategy (larger number of trees sampled). The relatively high chemical heterogeneity of the samples from Linarejos is also reflected by the relatively large distances of Pn-LIN samples to their group centroid in $\left[\mathrm{DF} 1_{\mathrm{T}}-\mathrm{DF} 2_{\mathrm{T}}\right]$ space (Fig. 5). In fact, two samples of the training set and two of the validation set were grouped with Pn-LSA samples.

\section{Interpretation of absorption bands that discriminate between species and locations}

To elucidate the chemical features of the wood that allow the models to differentiate between species and sites, the interpretation was limited to the lignin and polysaccharide bands that were identified from the individual discriminant models $\left(\mathrm{DF}_{\mathrm{L}}\right.$ and $\left.\mathrm{DF}_{\mathrm{P}}\right)$ and by the global model $\left(\mathrm{DF}_{\mathrm{T}}\right)$, i.e. the bands at 860 and $1425 \mathrm{~cm}^{-1}$ for lignin and 900, 1105, 1315, 1335, 1385, 1635 and $1655 \mathrm{~cm}^{-1}$ for 

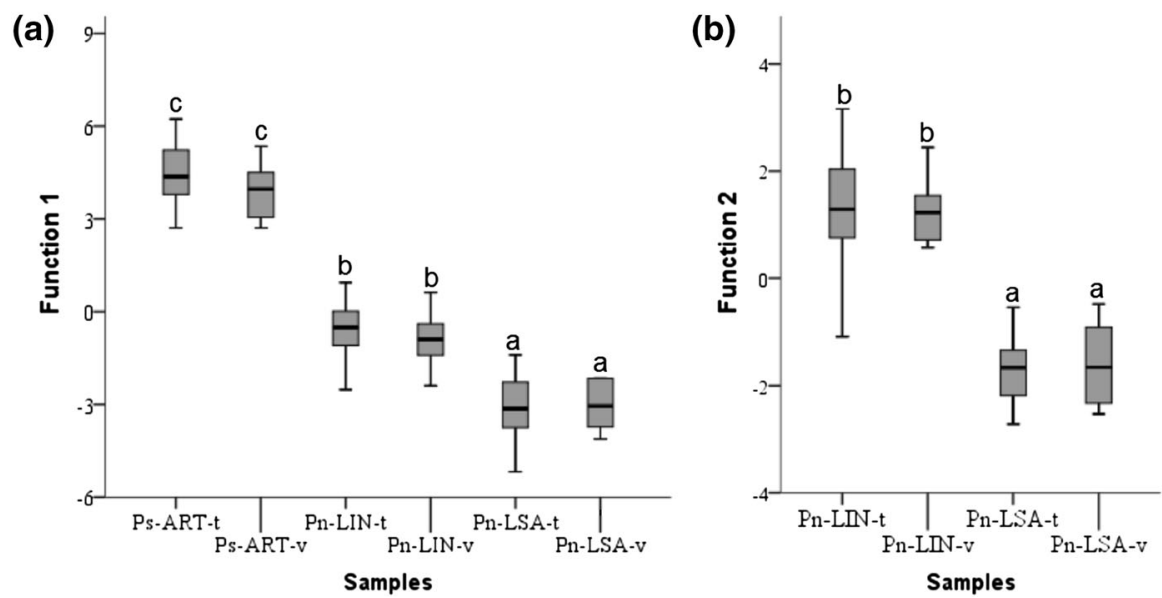

Fig. 6 Boxplot of the discriminant scores of the training set (t) and validation set (v) displaying the accuracy of the discriminant model a: discriminant function 1 ; $\mathbf{b}$ : discriminant function 2 . Groups are classified using Student-Newman-Keuls post hoc test $(P<0.001)$ in ascending order with label $(a, b$, and $c$ )

polysaccharides. The standardized canonical coefficients for the discriminant function are provided in Table 3. Bands with positive standardized canonical discriminant coefficients for $\mathrm{DF}_{\mathrm{T}}$ are more intense in Ps-ART samples (positive discriminant scores) and bands with negative coefficients are more intense in PnLIN and Pn-LSA samples (negative discriminant scores), whereas bands with positive coefficients for $\mathrm{DF}_{\mathrm{T}}$ show higher absorption in Pn-LIN samples (positive discriminant scores) and bands with negative coefficients show higher absorption in Pn-LSA samples (negative discriminant scores).

\section{Lignin absorption bands}

Firstly, the band at $860 \mathrm{~cm}^{-1}$ is associated with the $\mathrm{CH}$ out of plane bond vibrations in guaiacyl lignin (Evans 1991; Sills and Gossett 2012; Zhou et al. 2015). The positive standardized coefficient of this band implies that its absorbance is relatively strong in Pinus sylvestris wood. However, the band at $860 \mathrm{~cm}^{-1}$ can also be attributed to the propanoid side chain in lignin (Scheinmann 1970; Sharma 2004). Secondly, the band at $1425 \mathrm{~cm}^{-1}$ is assigned to the $\mathrm{CH}$ asymmetric deformation in methoxyl and aromatic skeletal vibrations in lignin (Faix 1992; Kubo and Kadla 2005). In this case, the standardized coefficients are negative, so that this band is associated with Pinus nigra samples. This suggests that aromatic methoxyl groups may be slightly more abundant in the structure of lignin in the Pinus nigra samples than the Pinus sylvestris samples.

These differences in lignin structure can be related to the lower shade tolerance of Pinus sylvestris than Pinus nigra (Trasobares et al. 2004). Lignin is the most receptive wood component to interactions with electromagnetic energy because of its macromolecular architecture (Chang et al. 1982). This higher sensitivity of Pinus 
Table 3 Standardized canonical discriminant function coefficients for the $\mathrm{DF}_{\mathrm{T}}$

\begin{tabular}{lrr}
\hline Bands $\left(\mathrm{cm}^{-1}\right)$ & \multicolumn{1}{c}{$\mathrm{DF} 1_{\mathrm{T}}$} & DF2 ${ }_{\text {Total }}$ \\
\hline 860 & 2.33 & -0.23 \\
900 & -1.56 & 1.44 \\
1105 & 1.62 & 1.08 \\
1225 & -1.13 & -0.94 \\
1315 & -1.83 & -3.83 \\
1335 & 1.70 & 5.15 \\
1385 & 2.21 & 1.11 \\
1405 & 2.10 & 1.55 \\
1425 & -3.44 & -0.94 \\
1610 & 1.09 & -1.31 \\
1635 & -4.28 & 0.95 \\
1655 & 3.52 & -1.91 \\
\hline
\end{tabular}

sylvestris may be due to the lignin structure in the middle lamella, which is sensitive to sunlight exposure. Evans et al. (1992) showed that the $\mathrm{CH}$ out of plane bending vibration is the most influenced by factors that modify wood lignin composition. Thus, it is assumed that in Pinus sylvestris lignin structures with more $\mathrm{CH}$ out band bending vibration are produced in order to maintain phenylpropane derivatives, which are considered to protect meristem cells against light stress (Higuchi 1997).

The lignin signature was not useful for distinguishing different growing locations.

\section{Polysaccharide absorption bands}

For species differentiation, the band at $1635 \mathrm{~cm}^{-1}$ is relatively strong in Pinus nigra, whereas the band at $1655 \mathrm{~cm}^{-1}$ was associated with Pinus sylvestris samples. Both bands are related to $\mathrm{OH}$ bond vibrations including intermolecular hydrogen bonds between polysaccharide chains (Genest et al. 2013; Karunakaran et al. 2015). The intensity of hydrogen bonding exhibits strong influence on the rigidity of the cellulose chain and provides mechanical stability in fibres (Higuchi 1997; Klemm et al. 2004; Popescu et al. 2009). Karunakaran et al. (2015) stated that the band near $1635 \mathrm{~cm}^{-1}$ is characteristic of insoluble xylan. Insolubility could be due to the strong hydrogen bonds that lead to a large interaction between xylan chains (Poletto et al. 2014). Therefore, it is hypothesized that there are stronger interactions between xylan chains in Pinus nigra than in Pinus sylvestris. It had previously been found that xylan content could vary between wood species, even from the same genus (Timell 1964; Sjostrom 1981).

Regarding the differentiation of growing locations on the basis of polysaccharide FTIR signatures, the band near $900 \mathrm{~cm}^{-1}$ is stronger for pine samples from Linarejos (Pn-LIN) than for La Sagra Mountain (Pn-LSA). This band corresponds to the $\mathrm{CH}$ deformation of $\beta$-glycosidic linkages, which is related to the abundance of amorphous cellulose (Faix and Böttcher 1992; Evans et al. 1992). The bands at 1105 and $1385 \mathrm{~cm}^{-1}$ are assigned to the $\mathrm{C}-\mathrm{O}$ stretching in cellulose and hemicellulose 


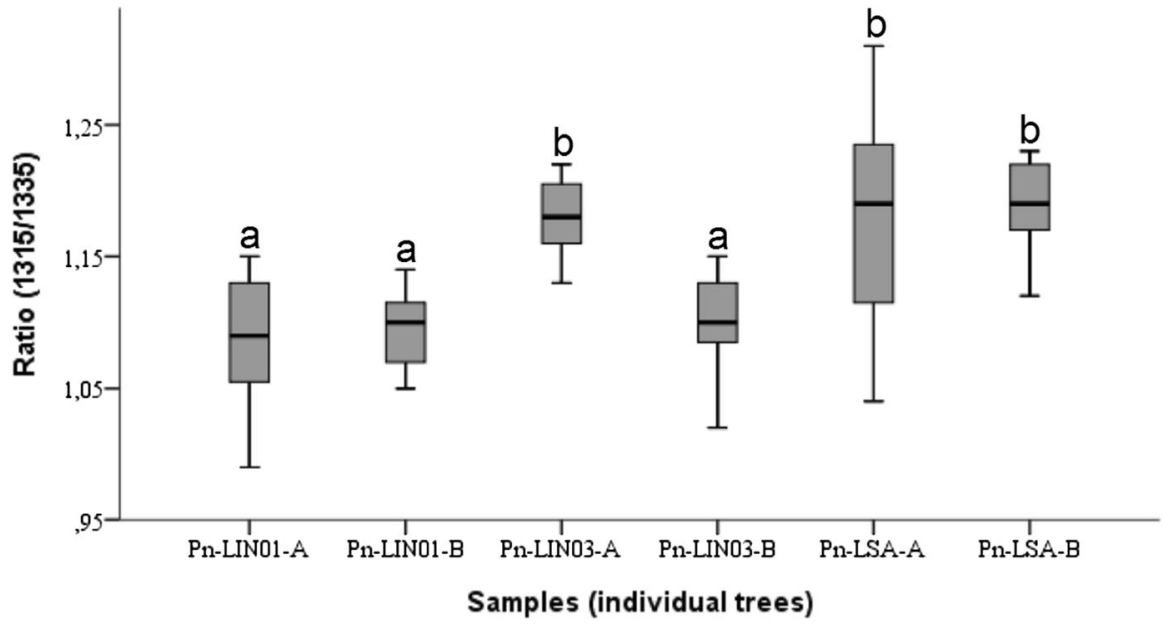

Fig. 7 Boxplot of the ratio for amorphous-to-crystalline cellulose $\left(1315 / 1335 \mathrm{~cm}^{-1}\right)$ for Pinus nigra trees. Groups are classified using Student-Newman-Keuls post hoc test $(P<0.001)$ in ascending order $(\mathbf{a}, \mathbf{b})$

(Faix 1991; McCann et al. 1992; Zhang et al. 2010); however, the former, with a positive coefficient, seems to be associated with Pn-LIN samples while the latter, with a negative coefficient, seems associated with the Pn-LSA samples. There is no convincing explanation for this observation.

The bands at 1335 and $1315 \mathrm{~cm}^{-1}$ are assigned to amorphous and crystalline cellulose, respectively (Colom and Carrillo 2005; Popescu et al. 2007). Samples from the Cazorla Mountain (Pn-LIN) had higher intensities of the band corresponding to the amorphous cellulosic structure, while samples from La Sagra Mountain (Pn-LSA) were characterized by higher intensities of the crystalline structure of cellulosic compounds. Indeed, the ratio between crystalline and amorphous cellulose bands $\left(1315 / 1335 \mathrm{~cm}^{-1}\right)$ indicates a relatively high degree of crystallinity in samples from LSA (Fig. 7). This ratio has been used as an empirical crystallinity index to compare amorphous and crystalline cellulose between hardwood and softwood (Colom et al. 2003; Colom and Carrillo 2005). The ANOVA test indicated that cellulose crystallinity is significantly higher $(P<0.001)$ in samples from La Sagra Mountain (Pn-LSA) than in those from Linarejos (PnLIN).

\section{Conclusion}

It is concluded that the FTIR-ATR in combination with discriminant analysis allows to distinguish between the pine species studied (Pinus nigra and Pinus sylvestris) with high reliability, whereas the models also provide strong indications of geographic origin, at least for the two stands of Pinus nigra studied here. It appeared that the lignin composition can provide information on pine species, whereas the 
polysaccharide fingerprints and, in particular, its degree of crystallinity, are informative on both species and forest location. Even though the chemical background of the discriminant functions cannot be fully understood from this kind of analysis, these results show that FTIR fingerprinting is a useful tool for provenancing of extant wood. Despite this, a larger sample (i.e. more trees) would be recommendable in future studies to check for the consistency of the performance of the models. The current approach may also be applied to provenancing archaeological wood, in which the discriminating features are sufficiently well preserved. This will be further explored in upcoming studies.

Acknowledgements This study was developed within the framework of the ForSeaDiscovery project (PITN-2013-GA607545) funded by the European Research Council through the Seventh Framework Programme under Grant Agreement Number 607545. We would like to thank the editor and reviewers for their time and insightful suggestions.

Open Access This article is distributed under the terms of the Creative Commons Attribution 4.0 International License (http://creativecommons.org/licenses/by/4.0/), which permits unrestricted use, distribution, and reproduction in any medium, provided you give appropriate credit to the original author(s) and the source, provide a link to the Creative Commons license, and indicate if changes were made.

\section{References}

Bjarnestad S, Dahlman O (2002) Chemical compositions of hardwood and softwood pulps employing photoacoustic Fourier transform infrared spectroscopy in combination with partial least-squares analysis. Anal Chem 74(22):5851-5858

Bodirlau R, Teaca CA (2009) Fourier transform infrared spectroscopy and thermal analysis of lignocelluloses fillers treated with organic anhydrides. Rom J Phys 54(1-2):93-104

Boeriu CG, Bravo D, Gosselink RJA, van Dam JEG (2004) Characterisation of structure-dependent functional properties of lignin with infrared spectroscopy. Ind Crop Prod 20:205-218

Carballo-Meilán A, Goodman AM, Baron MG, Gonzalez-Rodriguez J (2016) Application of chemometric analysis to infrared spectroscopy for the identification of wood origin. Cellulose 23:901-913

Castro F (2008) In search of unique iberian ship design concepts. Hist Archaeol 42:63-87

Chang ST, Hon DNS, Feist WC (1982) Photodegradation and photoprotection of wood surfaces. Wood Nad Fiber 14(2):104-117

Chen H, Ferrari C, Angiuli M, Yao J, Raspi C, Bramanti E (2010) Qualitative and quantitative analysis of wood samples by Fourier transform infrared spectroscopy and multivariate analysis. Carbohyd Polym 82:772-778

Colom X, Carrillo F (2005) Comparative study of wood samples of the northern area of Catalonia by FTIR. J Wood Chem Technol 25:1-11

Colom X, Carrillo F, Nogués F, Garriga P (2003) Structural analysis of photodegraded wood by means of FTIR spectroscopy. Polym Degrad Stabil 80:543-549

Creber GT, Chaloner WG (1984) Influence of environmental factors on the wood structure of living and fossil trees. Bot Rev 50:357-448

Enescu CM, de Rigo D, Caudullo G, Mauri A, Houston Durrant T (2016) Pinus nigra in Europe: distribution, habitat, usage and threats. In: San-Miguel-Ayanz J, de Rigo D, Caudullo G, Houston Durrant T, Mauri A (eds) European atlas of forest tree species. Publ. Off. EU, Luxembourg, p e015138+

Esteves B, Marques AV, Domingos I, Pereira H (2013) Chemical changes of heat treated pine and eucalypt wood monitored by FTIR. Maderas-Cienc Tecnol 15:245-258

Evans PA (1991) Differentiating "hard" from "soft" woods using Fourier transform infrared and Fourier transform Raman spectroscopy. Spectrochim Acta 47:1441-1447 
Evans PD, Michell AJ, Schmalzl KJ (1992) Studies of the degradation and protection of wood surfaces. Wood Sci Technol 26:151-163

Faix O (1991) Classification of lignin's from different botanical origins by FTIR spectroscopy. Holzforschung 45:21-27

Faix O (1992) Fourier transform infrared spectroscopy. In: Lin SY, Dence CW (eds) Methods in lignin chemistry. Springer, Berlin

Faix O, Böttcher JH (1992) The influence of particle size and concentration in transmission and diffuse reflectance spectroscopy of wood. Holz Roh-Werkst 50:221-226

Faix O, Böttcher JH (1993) Determination of phenolic hydroxyl group contents in milled wood lignins by ftir spectroscopy applying partial least-squares (PLS) and principal components regression (PCR). Holzforschung 47:45-49

Fritts HC (1976) Tree rings and climate. Academic Press, London

Gandolfo DS, Mortimer H, Woodhall JW, Boonham N (2016) Fourier transform infra-red spectroscopy using an attenuated total reflection probe to distinguish between Japanese larch, pine and citrus plants in healthy and diseased states. Spectrochim Acta A 163:181-188

Genest S, Salzer R, Steiner G (2013) Molecular imaging of paper cross sections by FT-IR spectroscopy and principal component analysis. Anal Bioanal Chem 405:5421-5430

Herrera R, Erdocia X, Llano-Ponte R, Labidi J (2014) Characterization of hydrothermally treated wood in relation to changes on its chemical composition and physical properties. J Anal Appl Pyrol 107:256-266

Higuchi T (1997) Biochemistry and molecular biology of wood. Springer, Berlin

Holmgren A, Bergström B, Gref R, Ericsson A (1999) Detection of pinosylvins in solid wood of scots pine using Fourier transform raman and infrared spectroscopy. J Wood Chem Technol 19:139-150

Hori R, Sugiyama J (2003) A combined FT-IR microscopy and principal component analysis on softwood cell walls. Carbohyd Polym 52:449-453

Houston Durrant T, de Rigo D, Caudullo G (2016) Pinus sylvestris in Europe: distribution, habitat, usage and threats. In: San-Miguel-Ayanz J, de Rigo D, Caudullo G, Houston Durrant T, Mauri A (eds) European atlas of forest tree species. Publ. Off. EU, Luxembourg, p e016b94+

Huang A, Zhou Q, Liu J, Fei B, Sun S (2008) Distinction of three wood species by Fourier transform infrared spectroscopy and two-dimensional correlation IR spectroscopy. J Mol Struct 883-884:160-166

Karunakaran C, Christensen CR, Gaillard C, Lahlali R, Blair LM, Perumal V, Miller SS, Hitchcock AP (2015) Introduction of Soft X-ray spectromicroscopy as an advanced technique for plant biopolymers research. PLoS ONE 10(3):e0122959

Klemm D, Philipp B, Heinze T, Heinze U, Wagenknecht W (2004) General considerations on structure and reactivity of cellulose: section 2.1-2.1.4. Compr Cell Chem I:9-29

Krakau UK, Liesebach M, Aronen T, Lelu-Walter MA, Schneck V (2013) Scots pine (Pinus sylvestris L.). In: Pagues LE (ed) Forest tree breeding in Europe: current state-of-the-art and perspectives. Managing forest ecosystems, vol 25. Springer, Dordrecht, pp 267-323. https://doi.org/10.1007/97894-007-6146-9_6

Kubo S, Kadla JF (2005) Hydrogen bonding in lignin: a Fourier transform infrared model compound study. Biomacromol 6(5):2815-2821

Labbé N, Harper D, Rials T (2006) Chemical structure of wood charcoal by infrared spectroscopy and multivariate analysis. J Agr Food Chem 54:3492-3497

Liang C, Marchessault R (1959) Infrared spectra of crystalline polysaccharides. II. Native celluloses in the region from 640 to $1700 \mathrm{~cm}$. J Polym Sci 39(135):269-278

López-Merino L, Silva Sánchez N, Kaal J, López-Sáez JA, Martínez Cortizas A (2012) Post-disturbance vegetation dynamics during the Late Pleistocene and the Holocene: an example from NW Iberia, Global Planet. Change 92-93:58-70

Manninen AM, Tarhanen S, Vuorinen M, Kainulainen P (2002) Comparing the variation of needle and wood terpenoids in Scots pine provenances. J Chem Ecol 28:211-228

McCann MC, Hammouri M, Wilson R, Belton PS, Roberts K (1992) Fourier transform infrared microspectroscopy Is a new way to look at plant cell walls. Plant Physiol 100:1940-1947

Mizzoni F, Cesaro SN (2007) Study of the organic residue from a 2600-year old Etruscan plumpekanne. Spectrochim Acta A 68:377-381

Mohebby B (2008) Application of ATR infrared spectroscopy in wood acetylation. J Agric Sci 10:253-259

Moore AK, Owen NL (2001) Infrared spectroscopic studies of solid wood. Appl Spectrosc Rev 36:65-86 
Nuopponen M, Vuorinen T, Jämsä S, Viitaniemi P (2003) The effects of a heat treatment on the behaviour of extractives in softwood studied by FTIR spectroscopic methods. Wood Sci Technol 37:109-115

Oliva AG, Baonza MV, Fernández-Golfín SJI, Conde GM, Hermoso PE (2006) Effect of growth conditions on wood density of Spanish Pinus nigra. Wood Sci Technol 40:190-204

Pandey KK (1999) A study of chemical structure of soft and hardwood and wood polymers by FTIR spectroscopy. J Appl Polym Sci 71:1969-1975

Pandey KK (2005) A note on the influence of extractives on the photo-discoloration and photodegradation of wood. Polym Degrad Stabil 87:375-379

Pandey KK, Pitman AJ (2003) FTIR studies of the changes in wood chemistry following decay by brownrot and white-rot fungi. Int Biodeter Biodegr 52:151-160

Poletto M, Ornaghi Júnior HL, Zattera AJ (2014) Native cellulose: structure, characterization and thermal properties. Materials 7(9):6105-6119

Popescu CM, Popescu MC, Singurel G, Vasile C, Argyropoulos DS, Willfor S (2007) Spectral characterization of eucalyptus wood. Appl Spectrosc 61:1168-1177

Popescu CM, Singurel G, Popescu MC, Vasile C, Argyropoulos DS, Willfor S (2009) Vibrational spectroscopy and X-ray diffraction methods to establish the differences between hardwood and softwood. Carbohyd Polym 77:851-857

Rana R, Müller G, Naumann A, Polle A (2008) FTIR spectroscopy in combination with principal component analysis or cluster analysis as a tool to distinguish beech (Fagus sylvatica L.) trees grown at different sites. Holzforschung 62:530-538

Reyes O, Casal M (2004) Effects of forest fire ash on germination and early growth of four Pinus species. Plant Ecol 175:81-89

Rowell RM, Pettersen R, Han JS, Rowell JS, Tshabalala MA (2005) Cell wall chemistry. In: Handbook of wood chemistry and wood composites. www.crcpress.com. ISBN: 0-8493-1588-3

Santoni I, Callone E, Sandak A, Sandak J, Dirè D (2015) Solid state NMR and IR characterization of wood polymer structure in relation to tree provenance. Carbohyd Polym 117:710-721

Scheinmann F (1970) An introduction to spectroscopic methods for the identification of organic compounds, Vol 1. Pergamon Press, Oxford

Schwanninger M, Rodrigues JC, Pereira H, Hinterstoisser B (2004) Effects of short-time vibratory ball milling on the shape of FT-IR spectra of wood and cellulose. Vib Spectrosc 36:23-40

Sharma BK (2004) Instrumental methods of chemical analysis, introduction to analytical chemistry, 23rd edn. Goel Publishing House, Meerut

Shearer GL (1989) An evaluation of Fourier transform infrared spectroscopy for the characterization of organic compounds in art and archaeology. Ph.D. Dissertation, University of London

Sills DL, Gossett JM (2012) Using FTIR to predict saccharification from enzymatic hydrolysis of alkali pretreated biomasses. Biotechnol Bioeng 109:353-362

Sjostrom E (1981) Wood chemistry: fundamentals and applications. Academic Press, New York, p 293

Taylor AM, Gartner BL, Morrell JJ (2002) Heartwood formation and natural durability-a review. Wood Fiber Sci 34:58-611

Timell TE (1964) Wood hemicelluloses: part I. Adv Carbohyd Chem 19:247-302

Tiscar PA, Linares JC (2011) Pinus nigra subsp. Salzmannii forests from southeast Spain: using structure and process information to guide management. In: Frisiras CT (ed) Pine forests: types, threats and management. Nova Science Publishers, Hauppauge

Traoré M, Kaal J, Martínez Cortizas A (2016) Application of FTIR spectroscopy to the characterization of archeological wood. Spectrochim Acta A 156:63-70

Trasobares A, Pukkala T, Muna J (2004) Growth and yield model for uneven-aged mixtures of Pinus sylvestris L. and Pinus nigra Arn. in Catalonia, north-east Spain. Ann For Sci 61:9-24

Unger A, Schniewind AP, Unger W (2001) Conservation of wood artifacts. Springer, Berlin

Vahur S, Kriiska A, Leito I (2011) Investigation of the adhesive residue on the flint insert and the adhesive lump found from the pulli early mesolithic settlement site (Estonia) by micro-atr-ft-ir spectroscopy. Estonian J Archaeol 15:3-17

Wing J (2015) Roots of Empire: forests and state power in early modern Spain, c.1500-1750 (Brill: http:// www.brill.com/products/book/roots-empire)

Zhang YL, Chen J, Lei Y, Zhou Q, Sun S, Noda I (2010) Discrimination of different red wine by Fouriertransform infrared and two-dimensional infrared correlation spectroscopy. J Mol Struct 974:144-150 
Zhang FD, Xu CH, Li MY, Chen XD, Zhou Q, Huang AM (2016) Identification of Dalbergia cochinchinensis (CITES Appendix II) from other three Dalbergia species using FT-IR and 2D correlation IR spectroscopy. Wood Sci Technol 50:693-704

Zhao J, Xiuwen W, Hu J, Liu Q, Shen D, Xiao R (2014) Thermal degradation of softwood lignin and hardwood lignin by TG-FTIR and Py-GC/MS. Polym Degrad Stab 108:133-138

Zhou C, Jiang W, Cheng Q, Via BK (2015) multivariate calibration and model integrity for wood chemistry using Fourier transform infrared spectroscopy. J Anal Methods Chem 2015:1-9 